\title{
Cryptorchidism and its Effects on Histomorphology of Testis in Paediatric Age Group
}

\author{
0. H. Radhika Krishna ${ }^{1}$, Mandakini T. Kotaiah ${ }^{2}$, K. Geetha ${ }^{3}$, Santosh Kiran G. ${ }^{4}$, Srinivas Reddy P. ${ }^{5}$, Ramesh Reddy Kota ${ }^{6}$
}

\author{
${ }^{1}$ Associate Professor, Department of Pathology, Osmania Medical College, Hyderabad, Telangana, India. \\ ${ }^{2}$ Assistant Professor, Department of Paediatric Surgery, Niloufer Hospital, Hyderabad, Telangana, India. \\ ${ }^{3}$ Assistant Professor, Department of Pathology, Niloufer Hospital, Hyderabad, Telangana, India. \\ ${ }^{4}$ Postgraduate Student, Department of Pathology, Osmania Medical College, Hyderabad, Telangana, India. \\ ${ }^{5}$ Professor, Department of Paediatric Surgery, Niloufer Hospital, Hyderabad, Telangana, India. \\ ${ }^{6}$ Professor, Department of Paediatric Surgery, Niloufer Hospital, Hyderabad, Telangana, India.
}

\section{ABSTRACT}

\section{BACKGROUND}

Numerous histological studies on undescended testis have attempted to understand the pathophysiology of cryptorchidism and have helped in the clinical management of this congenital aberration. Undescended testis is associated with high risk of infertility and cancer. This study was performed on orchidectomy specimens of cryptorchidism at a tertiary paediatric referral centre in order to understand the histological changes of cryptorchidism and correlate them with age.

\section{METHODS}

A retrospective study of 5 years was performed at a tertiary paediatric referral centre. 21 orchidectomy specimens of undescended testis were included in the study. Most of the cases were associated with torsion as orchidectomy was not performed for viable testis and a direct orchiopexy was done. Specimens with large areas of haemorrhage and necrosis were excluded and microscopically viable areas were studied. Seven histological criteria were taken into account and correlated with histology. An extensive review of literature was done.

\section{RESULTS}

Histology revealed that all the seven microscopic criteria taken into account including absence of germ cells were more severe with increasing age of the patients.

\section{CONCLUSIONS}

To avoid irreversible damage to germinal cells, orchiopexy should be performed early, and a simultaneous biopsy should be taken to know the degree of histological changes and to determine the necessity of institution of supplementary hormonal treatment. At the time of birth, cryptorchid testis do harbour germ cells. But from fifteen years of age onwards, germ cells decrease. In our study, most normal findings were observed in children of less than two years of age; afterwards there was a damage of tubules and epithelium and fibrosis of the stroma was seen. As proven by many studies earlier, orchiopexy is needed for cryptorchidism. Also, a testicular biopsy should be performed in older boys in order to give any hormonal supplementation if needed.

\section{KEY WORDS}

Cryptorchidism, Histology, Paediatric, Age Correlation
Corresponding Author: Dr. O. H. Radhika Krishna, Flat No. 301, Raghava Residency, Shantinagar, Masab Tank, Hyderabad-28, Telangana, India. E-mail: othulururadhika@yahoo.co.in

DOI: $10.14260 / \mathrm{jemds} / 2019 / 540$

Financial or Other Competing Interests: None.

How to Cite This Article:

Krishna OHR, Kotaiah MT, Geetha K, et al. Cryptorchidism and its effects on histomorphology of testis in paediatric age group. J. Evolution Med. Dent. Sci. 2019;8(31):2480-2484, $10.14260 / \mathrm{jemds} / 2019 / 540$

Submission 17-04-2019,

Peer Review 16-07-2019,

Acceptance 22-07-2019,

Published 05-08-2019. 


\section{BACKGROUND}

Absence of one or both testes from the scrotum is referred to as cryptorchidism. Failure of testis to move from an abdominal position through the inguinal canal into the ipsilateral scrotum during fetal development characterizes this condition. Aetiology of cryptorchidism is unknown. Multifactorial origin is postulated. Risk of germ cell tumours is very high in cryptorchid testis. Cryptorchidism is also associated with impaired spermatogenesis. The abdominal temperature, in the inguinal canal or abdominal cavity is nearly $2^{\circ} \mathrm{C}$ higher than scrotal and probably is the cause of impaired spermatogenesis and germ cell damage, especially between the 6th month and 2nd year of life Under the influence of androgens, several factors were found to be responsible for testicular descent, traction vas and vessels, differential growth of the body gubernaculums, a high intra-abdominal pressure, development and maturation of the epididymis. Beginning in the seventh month of gestation the gonad, which lies at the top of the gubernaculum, slips rapidly into the testis. The scrotal part of the processus vaginalis persists as the tunica vaginalis and the upper part obliterates. Independent of race and geographical region, cryptorchidism represents one of common disorders of childhood. It is one of the most common congenital disorders with a prevalence of 2-5\%.[1,2,3] Risk of infertility and testicular malignancy associated with cryptorchidism can be significantly reduced by correction surgery, orchiopexy.

Over the last few decades age of orchiopexy decreased from $10-15$ years in 1950 s ${ }^{[4]}$ to $5-6$ years in $1970 s^{[5]}$ to $1-2$ in $1990 s^{[6]} \& 2000 .{ }^{[7]}$ However, the age at which intervention is sought is higher than recommended age. Orchidectomy is performed where orchiopexy is not feasible. We studied the histological changes in the orchidectomy specimens and correlated with patients age to understand the disadvantages of late surgical intervention and the degree of testicular histological deviation with increasing age. We have considered all the cases of undescended testes. Most common reason for orchidectomy is torsion. However, testis with severe gangrenous changes were excluded from the study.

\section{METHODS}

This study was a retrospective study of 5 years duration at a tertiary paediatric referral centre. 21 total orchidectomy specimens of undescended abdominal testes were studied. Clinical data was analysed, and the cases were categorized in groups according to age < 1 year of age (Group 1), $1-3$ years (Group 2), 4 - 7 years (Group 3) and 7 - 13 years age (Group 4) age groups respectively. Histological sections given from the testis were examined under light microscope. At least fifty cross sectional tubules were counted per case. The histopathological findings were analysed on H\&E stain slides and the findings taken into considerations were interstitial fibrosis, tubular sclerosis, Sertoli nodules, Leydig cell hyperplasia, Intertubular germ cell neoplasia, arrest of spermatogenesis, apparent tubular loss. These findings were correlated with age and their incidence in each age group was assessed.

\section{RESULTS}

Most of the cases were in the older age group i.e. 7 - 13 years and presented with pain abdomen. Five patients were less than a year of age. Interstitial fibrosis was more in older children as was atrophic seminiferous tubules and arrest of spermatogonia. Tubular changes were also more with increasing age. Leydig cell hyperplasia \& Sertoli nodules were more in older patients. We did not encounter intratubular germ cell neoplasia in any of our cases. The adnexal structure, epididymis showed changes of vascular congestion as most of these cases were post torsion.

\begin{tabular}{|c|c|}
\hline Age in Years ( $\mathbf{n = 2 1 )}$ & Total No. of Cases ( \%) \\
\hline$<1$ year & $5 \operatorname{cases}(25 \%)$ \\
\hline $1-3$ years & $6 \operatorname{cases}(28 \%)$ \\
\hline $4-7$ years & $4 \operatorname{cases}(19 \%)$ \\
\hline $7-13$ years & $6 \operatorname{cases}(28 \%)$ \\
\hline \multicolumn{2}{|c|}{ Table 1. Age Incidence } \\
\hline
\end{tabular}

\begin{tabular}{|c|c|c|c|c|c|c|c|}
\hline 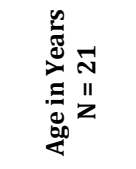 & 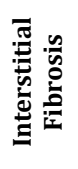 & 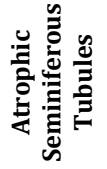 & 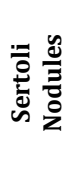 & 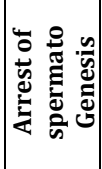 & 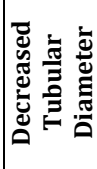 & 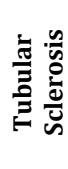 & 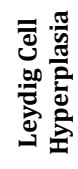 \\
\hline $\begin{array}{l}<1 \text { Year } \\
5 \text { Cases }\end{array}$ & 1 & 0 & 1 & 1 & 1 & 0 & 0 \\
\hline $\begin{array}{c}1-3 \text { Years } \\
6 \text { Cases }\end{array}$ & 2 & 2 & 2 & 1 & 1 & 0 & 0 \\
\hline $\begin{array}{c}4 \text { - } 7 \text { Years } \\
4 \text { Cases }\end{array}$ & 4 & 4 & 2 & 4 & 4 & 1 & 5 \\
\hline $\begin{array}{c}7 \text { - } 13 \text { Years } \\
6 \text { Cases } \\
\end{array}$ & 5 & 5 & 2 & 6 & 6 & 2 & 4 \\
\hline
\end{tabular}
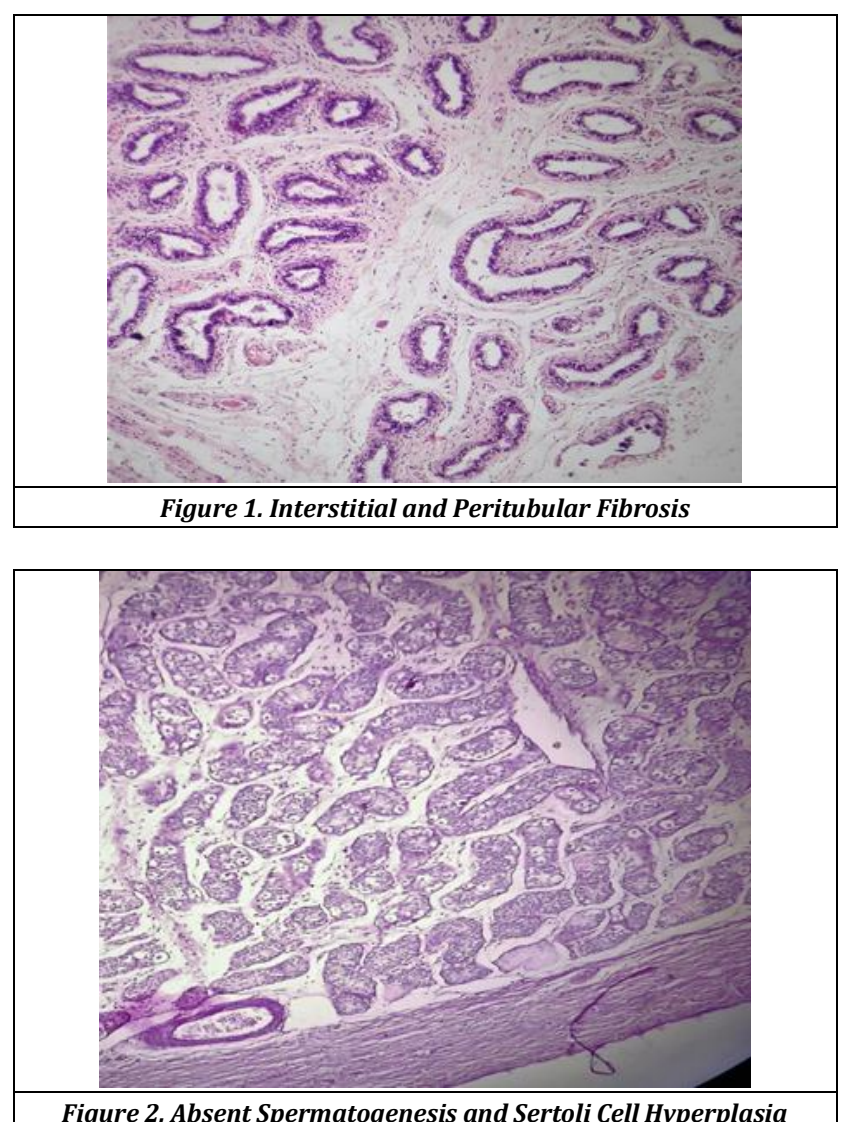

Figure 2. Absent Spermatogenesis and Sertoli Cell Hyperplasia 

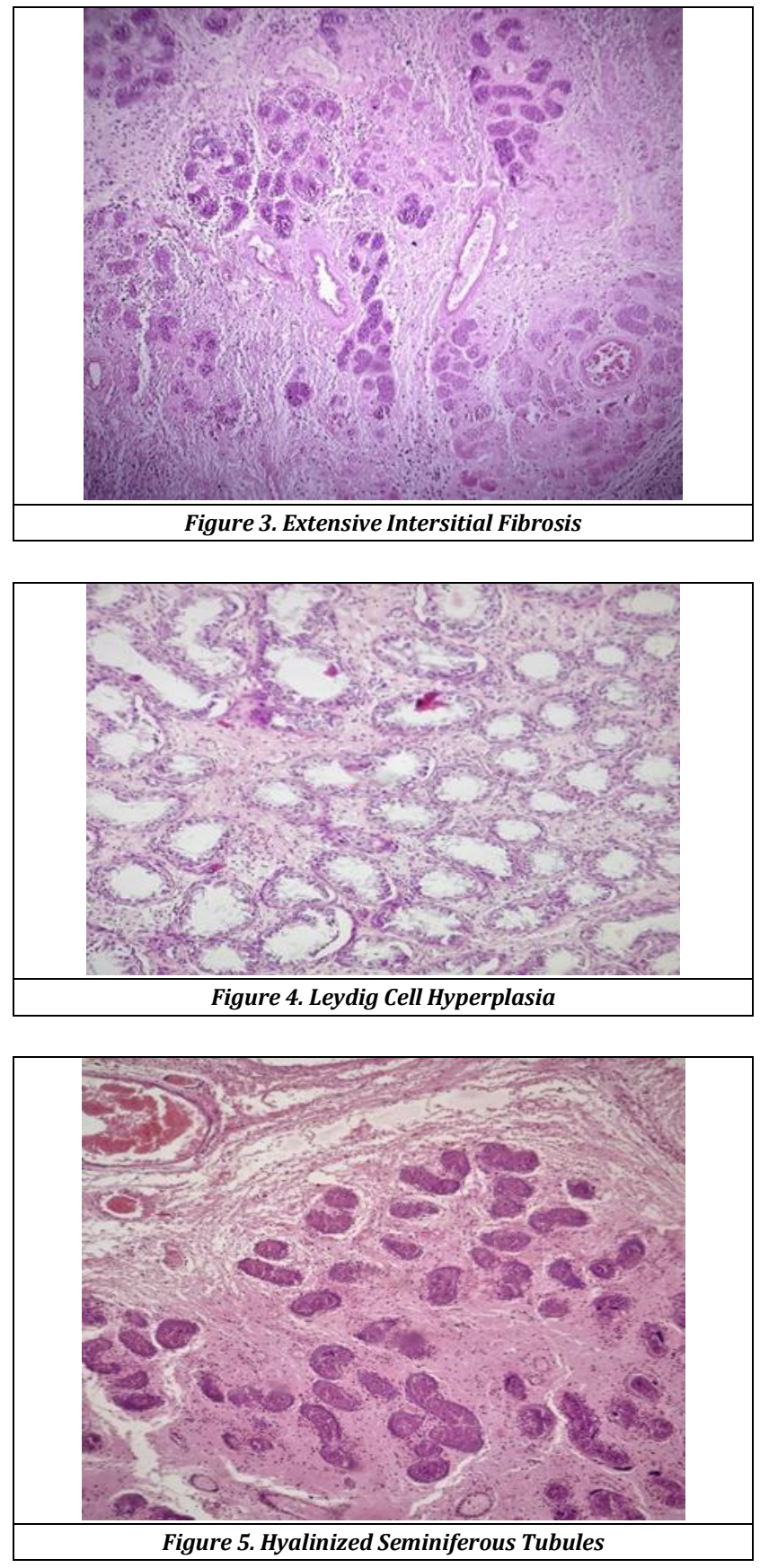

\section{DISCUSSION}

Over the last 4 - 5 decades our knowledge and understanding of undescended testis has increased. Deleterious influence of cryptorchidism in causing maldevelopment of germinal epithelium and spermatogenesis is better understood and its influence on the histology of undescended testis is unravelled. The main concerns in persistent undescended testis are malignancy and infertility.[6] In our study we found no significant differences in histopathological findings in different age groups of children with undescended testis. In the classic paper of Cooper ${ }^{[7]}$ smaller seminiferous tubules, fewer spermatogonia and more tubular tissue were found in cryptorchid testis appearing by 15 years of age. Most authors agree that histological status of testicular biopsies correlate with fertility variables (BJU). The germ cells in undescended testes correlate with the incidence of infertility. Many studies have revealed germ cells are normal in number at 6 months of age and thereafter there is gradual deterioration up to puberty. At puberty the size of cryptorchid testis decreases considerably and spermatogenesis is lost. We also noted that quite a good number of children presented at a higher age with pain abdomen a finding showing that the lack of testis in the scrotum did not warrant a medical consultation. Most patients in our institution are from the lower socioeconomic strata.

In the developing testis, before puberty maturation occurs in two steps. Initially in the first two to three months of life gonocytes are transformed into adult spermatogonia which forms the dividing cells for production of spermatogonia. They will provide a self-replicating pool of cells that will fuel future spermatogenesis.[8,9] Therefore in the first six months is associated with marked reduction in total number of germ cells per tubule. This phase is also associated with proliferation of LH \& FSH producing fetal Leydig cells and release a surge of testosterone in response to the rise in gonadotropins. The transformation of germ cells to primary spermatocytes occurs in the second stage around 3 - 5 years. ${ }^{[8]}$ The hypothalamic-pituitary gonadal hormone axis is transiently activated during the first months of life resulting in increased serum levels of follicle stimulating hormone (FSH), luteinizing hormone (LH), testosterone and inhibin B. higher levels of inhibin $\mathrm{B}$, persists for a longer period of time in comparison to the FSH and LH. Elevated levels of inhibin B remain for 15 months and come back to basal values at around 3 years of age. During the prepubertal period inhibin $B$ is secreted in detectable amounts, while FSH, LH and testosterone are extremely low.(8) around the third month of life the number of germ cells and the number of Leydig cells reach the maximum, and increased proliferation of the Sertoli cells takes place during the first 2-3 months of life. The changes in the FSH, LH and testosterone-values are replicated in the testicular histology. The transformation from gonocytes to the adult reservoir of germ stem cells, the Ad Spermatogonia starts in the third trimester, to be completed after the 6th month of life. This transformation does not occur in cryptorchidism and the gonocytes may persist until about 1.5 years of age. With no gonocyte transformation, no Spermatogonia A dark appear, and later on germ cells lack in testicular biopsies. Alterations occur in the undescended testis. They are not quiescent organs and progressive loss of germinal cells takes place. Intra-abdominal testis have highest risk of loss of germ cells.(10) It may reflect the higher temperature in abdominal location. ${ }^{[10]}$ Hittleman etal in their study results suggested a two percent risk per month for germ cell depletion and one percent risk per month for Leydig cell loss after one year of life.[11]

Cryptorchidism is associated with a lower postnatal increase of testosterone levels. Also associated with decreased or blunted response to LH \& FSH surge. Hadsiselimovic et al found that cryptorchid testis had significantly lower concentration of Leydig cells as compared to control testis,[4] Findings confirmed by Huff et al.[9] They found hypoplasia of Leydig cells in first 2 months of life and normal increase in Leydig cells at $3-4$ months did not occur in cryptorchid testis. [9] Tsain et al also examined biopsies of 274 boys who underwent orchiopexy showed the Leydig cell function is important in transformation of gonocytes to adult spermatogonia.[11] Increased fibrosis and decreased total germ cell count is directly proportional to age. 
Cryptorchid testis is associated with Leydig cell dysfunction and has deleterious effects on germ cell maturation. Cryptorchidism leads to decrease in total number of germ cells and maturation of spermatogonia after 1 year of age ${ }^{[9,11]}$ of Nistal et al. Huff et al in their study considered 5 parameters i.e. total germ cells, gonocytes, adult spermatogonia, primary spermatocytes and Leydig cell concentration in 459 cryptorchid testis and 356 of their descended partners. They found significant difference in the mean number of germ cells before 12 months. After 1-year the number of germ cells in cryptorchid testis was zero. In their study they proved that maturation of spermatogonia fails in cryptorchid testis and results in loss of total number of germ cells in adulthood. In 1982 Miniberg et al performed electron microscopy on testicular biopsy specimens taken at the time of orchiopexy.(12) They observed that the interstitial testicular architecture became disorganized the older a child was at the time of surgery. They also noted an increase in fibroblast number, collagen deposition and decrease in Leydig cell number. Suskind et al found decreased mean seminiferous tubular diameter, germ cell number and increased degree of fibrosis. Fibrosis was worse in older boys and associated with lesser tubular diameter.(13) Park et al found that the interstitial fibrosis was lower in boys less than 2 years in comparison to older boys.(14) The total germ cell count decreases the older a boy is with cryptorchid testis.(15) During the first 2 years of age the number of germ cells dramatically decrease ${ }^{(16)}$ report lack of germ cells from 15 months of age. The undescended testes are not quiescent organs during childhood as a progressive loss of germ cells takes place. Intra-abdominal testis has highest risk of no germ cells ${ }^{[10]}$ The thickening of seminiferous tubules basal membrane in cryptorchid testes is associated with pronounced fibrosis of the tubular lamina propria in cryptorchid boys There are suggestions that lesions of tubular membrane in cryptorchid testes might be related to the inhibited maturation/differentiation of Sertoli, Leydig and peritubular cells. The thickening of basal membrane increases with age in dysgenetic testes, indicating that age by itself may have a detrimental effect.

Rusuck et al studied 25 patients with a follow-up up to 18 years of age. they associated the fertility potential with histology and found that boys with severe histology were more likely to have sperm densities less than 20 million per cubic $\mathrm{mm}$. The number of spermatogonia per tubule corrected with correlated with semen analysis in boys with history of bilateral but not unilateral cryptorchidism.[17] In a study of 1335 cryptorchid boys who had biopsy of testis at the time of orchiopexy), it was found that total number of germ cells per tubule is not a good independent predictor of infertility in boys with unilateral cryptorchidism.[15] Adult spermatogonia assessment is more reliable indicator of future fertility potential. Hadziselimovic and Herzog found that sperm count and density was significantly decreased in males who had adult spermatogonia. Sertoli only cell syndrome predicts low fertility potential.[18] It has not been reported before 15 months. Cryptorchidism has to managed very early and if left untreated decreases the number of germ cells drastically within the first two years of life. Tseng et al found that early orchiopexy before one year of age showed improvement in tubular diameter, number of germ cells per tubule and degree of peritubular fibrosis and presence of Leydig cells. They also found that the undescended testis grew faster than the contralateral descended testis when orchiopexy is considered before one year of age.[6]

\section{CONCLUSIONS}

At the time of birth cryptorchid testis do harbour germ cells. But from fifteen years of age onwards, germ cells decrease. In our study, most normal findings were observed in children of less than two years of age; afterwards there was a damage of tubules, epithelium and fibrosis of the stroma. As proven by many studies earlier, orchiopexy is needed for cryptorchidism. Also, a testicular biopsy should be performed in older boys in order to give any hormonal supplementation if needed.

\section{REFERENCES}

[1] Cortes D, Kjellberg EM, Breddam M, et al. The true incidence of cryptorchidism in Denmark. J Urol 2008;179(1):314-8.

[2] Perazzo G. Surgical and hormonal therapy of cryptorchidism. Riforma Med 1950;64(38-39):1051-3.

[3] Mengel W, Hienz HA, Sippe WG 2nd, et al. Studies on cryptorchidism: a comparison of histological findings in the germinative epithelium before and after the second year of life. J Pediatr Surg 1974;9(4):445-50.

[4] Hadziselimovic F, Herzog B, Seguchi H. Surgical correction of cryptorchism at 2 years: electron microscopic and morphometric investigations. J Pediatr Surg 1975;10(1):19-26.

[5] Bruijnen CJ, Vogels HD, Beasley SW. Review of the extent to which orchiopexy is performed at the optimal age: implications for health services. ANZ J Surg 2008;78(11):1006-9.

[6] Tseng CS, Chiang IN, Hong CH, et al. Advantage of early orchiopexy for undescended testis: analysis of testicular growth percentage ratio in patients with unilateral undescended testicle. Sci Rep 2017;7(1):174-6.

[7] Cooper ER. The histology of the retained testis in the human subject at different ages and its comparison with the Scrotal testis. J Anat 1929;64(Pt 1):5-27.

[8] Hadziselimović F, Thommen L, Girard J, et al. The significance of postnatal gonadotropin surge for testicular development in normal and cryptorchid testes. J Urol 1986;136(1 Pt 2):274-6.

[9] Huff DS, Hadziselimović F, Snyder HM 3rd, et al. Early postnatal testicular maldevelopment in cryptorchidism. J Urol 1991;146(2(Pt 2):624-6.

[10] Cortes D, Thorup J, Petersen BL. Testicular histology in cryptorchid boys - aspects of fertility. J Ped Surg Special 2006;1:34-7.

[11] Tasian GE, Hittelman AB, Kim GE, et al. Age at orchiopexy and testis palpability predict germ and Leydig cell loss: clinical predictors of adverse histological features of cryptorchidism. J Urol 2009;182(2):704-9. 
[12] Mininberg DT, Rodger JC, Bedford JM. Ultrastructural evidence of the onset of testicular pathological conditions in the cryptorchid human testis within the first year of life. J Urol 1982;128(4):782-4.

[13] Suskind A, Hayner-Buchan P, Feustel PJ, et al. Fibrosis correlates with detailed histological analysis of human undescended testes. BJU Int 2008;101(11):1441-5.

[14] Park KH, Lee JH, Han JJ, et al. Histological evidences suggest recommending orchiopexy within the first year of life for children with unilateral inguinal cryptorchid testis. Int J Urol 2007;14(7):616-21.

[15] Mechlin CW, Kogan BA. What lessons can be learned from testicular histology in undescended testes? Transl Androl Urol 2014;3(4):365-9.
[16] Schindler AM, Diaz P, Cuendet A, et al. Cryptorchidism: a morphologic study of 670 biopsies. Helv Paediatr Acta 1987;42(2-3):145-58.

[17] Cortes D, Thorup JM, Visfeldt J. Cryptorchidism: aspects of fertility and neoplasms. A study including data of 1,335 consecutive boys who underwent testicular biopsy simultaneously with surgery for cryptorchidism. Horm Res 2001;55(1):21-7.

[18] Leissner J, Filipas D, Wolf HK, et al. The undescended testis: considerations and impact on fertility. BJU International 1999;83(8):885-92. 